\title{
A Research on The Botanical Composition of Handüzü Plateau
}

\author{
Adil Bakoğlu',a, Hüseyin Baykal ${ }^{1, b}$, Muhammed İkbal Çatal ${ }^{2, c, *}$ \\ ${ }^{I}$ Department of Plant and Animal Production, Faculty of Agriculture and Natural Sciences, Recep Tayyip Erdoğan University, 53100 Rize, Turkey \\ ${ }^{2}$ Department of Field Crops, Faculty of Agriculture and Natural Sciences, Recep Tayyip Erdoğan University, 53100 Rize, Turkey
} *Corresponding author

\begin{tabular}{l|l}
\hline A R T I C L E I N F O & A B S T R A C T \\
Research Article & $\begin{array}{l}\text { In this study, which was carried out in 2018, some vegetation characteristics of Handüzü plateau } \\
\text { which was connected to Güneysu district of Rize province was determined by using Lup method. } \\
\text { Canopy cover and botanical composition ratios and pasture status class were investigated in the } \\
\text { study. As a result of the study, } 4 \text { grasses, } 4 \text { legume and } 33 \text { other family plants were identified. The } \\
\text { rate canopy covering of the research area was } 82.40 \%, \text { the rate of grasses in the botanical } \\
\text { composition was } 33.37 \%, \text { the rate of the legumes was } 5.75 \% \text { and the ratio of the other families was } \\
60.88 \% . \text { The first three species, the most common found in pasture, respectively; Nardus stricta L. } \\
(27.00 \%), \text { Carex atrata L. subsp. aterrima (Hoppe) Hartm. (11.10\%) and Polygala alpestris Rchb. } \\
\text { Received : } 26 / 03 / 2019 \\
\text { Accepted : 09/08/2019 }\end{array}$ \\
$\begin{array}{l}\text { Keywords: } \\
\text { Handüzü }\end{array}$ & $\begin{array}{l}\text { was concluded that especially controlled grazing and top-seeding, were applied together other } \\
\text { methods of breeding. }\end{array}$
\end{tabular}

Botanical composition

Pasture status

Top-seeding

Türk Tarım - Gıda Bilim ve Teknoloji Dergisi 7(9): 1339-1343, 2019

\section{Handüzü Yaylasının Botanik Kompozisyonu Üzerine Bir Çalışma}

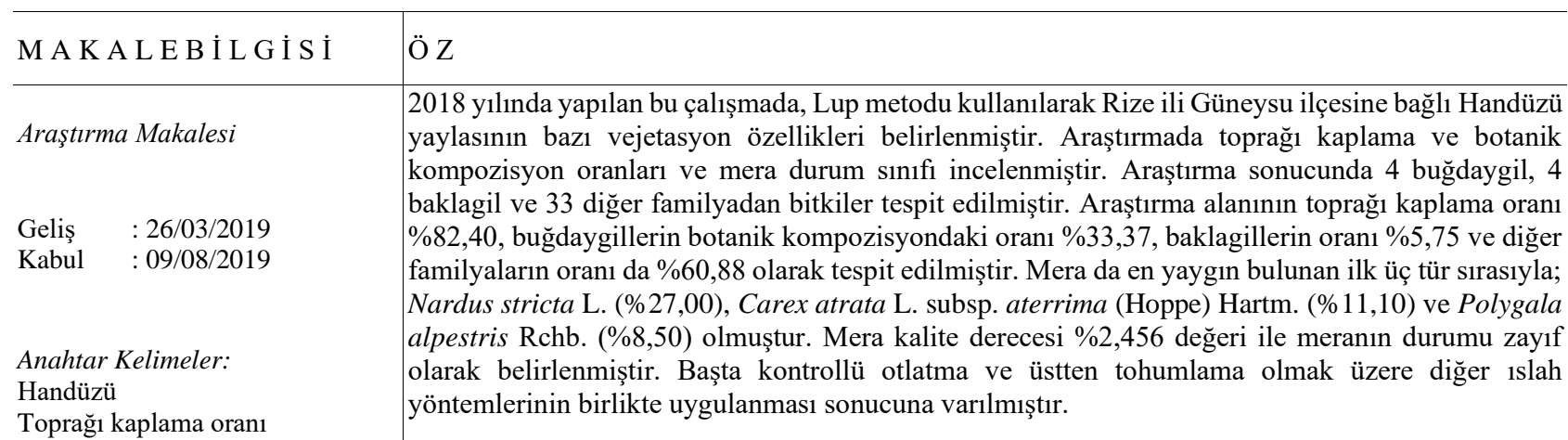

Botanik kompozisyon

Mera durumu

Üstten tohumlama 


\section{Giriş}

Türkiye, flora bütünlüğü bakımından ele alındığında üç fitocoğrafik bölgenin içerisinde bulunmaktadır. $\mathrm{Bu}$ bölgeler Kuzeyde Avrupa-Sibirya; Doğu ve Orta Anadolu'da İran-Turan; Güney ve Batıda ise Akdeniz fitocoğrafik bölgeleridir (Akdeniz, 2009). Üç flora merkezinin kesişme alanında yer almasının etkisiyle son yapılan araştırmalara göre, ülkemizde yaklaşık 12,000 bitki taksonu bulunduğu ve buna bağlı olarak ta endemizmin yüksek olduğu tespit edilmiştir.

Ülkemizin sahip olduğu en önemli doğal kaynakların başında yer alan mera varlığımız; yirminci yüzyılın ilk yarısından başlayarak, 44 milyon ha'dan yaklaşık olarak dörtte üç oranında azalarak, günümüzde 14,6 milyon ha'a kadar düşmüștür (Anonim, 2016). Rize ilinde ise toplam 45 332 ha çayır-mera alanı bulunmaktadır (Anonim, 2018).

Çayır mera alanlarında vejetasyon etüt ve ölçmeleri vejetasyonu iyi bilinmeyen bölgelerdeki çayır ve meraların kalitatif ve özellikle dekantitatif karakterleri hakkında bilgiler elde etmek için uygulanmaktadır (Türk ve ark., 2003).

Ülkemizin değişik bölgelerinde yapılan mera çalışmalarında farklı sonuçlar alınmıştır. Erzurum Palandökende buğdaygiller botanik kompozisyonda ortalama olarak \%56,28 oranında, baklagiller \%10,47 ve diğer familyalara ait türler \%33,31, toprağı kaplama oranı \%39 ve mera durumunun orta olduğu (Faretörbay, 2007), yine aynı bölgede mera durumunun zayıf olduğu (Bakoğlu ve Koç, 2002); Artvin'in Ardanuç ilçesi Aydın Köyü merasında botanik kompozisyonun ise \%46,19 ile buğdaygillerden, \%14,36 ile baklagillerden ve \%39,45 ile diğer familyalardan oluştuğu (Bilgin, 2010); Tokat İli Merkez Yeşilyurt köyü doğal merasında buğdaygiller $\% 34,11$, baklagiller \%33,41 ve diğer familyaya giren bitki oranının \%32,49 olduğu (Nadir ve ark., 2012); Amasya meralarında bitkiyle kaplı alan oranı $\% 77,8$, buğdaygillerin oran1 $\% 41,81$, baklagillerin $\% 22,84$ ve diğer familyadan türlerin \%35,35 olduğu (Yavuz ve ark., 2012); Bingöl'de meranın \%85,8'inin bitki ile kaplı olduğunu, kaplama alanına göre botanik kompozisyonun \%59,9'unu buğdaygil, $\% 2,8$ 'ini baklagiller ve \%37,3'ünü diğer familya bitkilerinin oluşturduğunu (Ağın ve Kökten, 2013); Elazığ ili, Karakoçan ilçesi, Bahçecik Köyü'nde meranın \%79,7'sinin bitki ile kaplı olduğu, kaplama alanına göre botanik kompozisyonun \%44,3'ünün buğdaygiller, \%9,8'ini baklagiller ve \%45,9'unu diğer familya bitkilerinin oluşturduğu (Taşdemir, 2015); Kastamonu ili, Taşköprü ilçesine bağlı 12 köyün doğal meralarında yapılan çalışmalarda bitkiyle kaplı alan oranı ortalaması \%83,34, meraların 1 adedi "İyi", 5 adedi "Orta" ve 6 adedi ise "Zayıf" mera durumu olduğu (İspirli ve ark., 2016); Bartın ili, merkez ilçesine bağlı 15 köyün meralarının bitkiyle kaplı alan oranı ortalaması \%93,57, meraların 1 adedi "Çok iyi", 1 adedi "İyi", 6 adedi "Orta" ve 7 adedi ise "Zayıf" mera durumu sinıfina girdiği (Uzun ve ark., 2016); Isparta ili Davraz Dağı Kozağacı Yaylası Kocapınar merasında botanik kompozisyonunda, toplam buğdaygil oran1 \%60,9, baklagil oran $\% 14,4$ diğer familyalara giren tür oranları ise $\% 24,7$ ve bitki ile kaplı alan oranı $\% 24,3$ olduğu (Babalık ve Fakır, 2017); Adana İli Tufanbeyli ilçesi meralarında buğdaygiller oranı ortalamas $\% 36,9$, baklagiller $\% 22,0$ ve diğer familya bitkileri oranı $\% 41,1$, mera kalite derecelerinin 2,40-3,92 arasında değiştiği ve meraların durum sınıfının zayıf olduğu araştırıcılar tarafından tespit edilmiștir (Çınar ve ark., 2019).

Rize ili'nde çayır ve mera alanlarını da içeren bazı floristik, fitososyolojik ve etnobotanik çalışmalar (Çobanoğlu 2012; Baykal ve Atamov 2016, 2017, 2018; Baykal vd., 2018) yapılmış olmasına karşın mera özelliklerini içeren detaylı çalışmalar mevcut değildir.

$\mathrm{Bu}$ çalışmanın amacı, Handüzü mera vejetasyonunun bitki tür ve gruplarını belirleyerek bölgedeki meraların durumunu ortaya koymak, mera amenajmanı ve 1slah programlarına ışık tutmaktır.

\section{Materyal ve Metot}

\section{Materyal}

$\mathrm{Bu}$ araştırma 2018 yılında Rize ili Güneysu İlçesine bağlı deniz seviyesinden yaklaşık $1850 \mathrm{~m}$ yükseklikte (4052'51" N, 40³9'11" E) ve ilçeye 16 km uzaklıkta bulunan Handüzü yaylasında yürütülmüştür (Resim 1). Çalışma sahasından çekilen bazı fotoğraflar Resim 2'de verilmiştir.
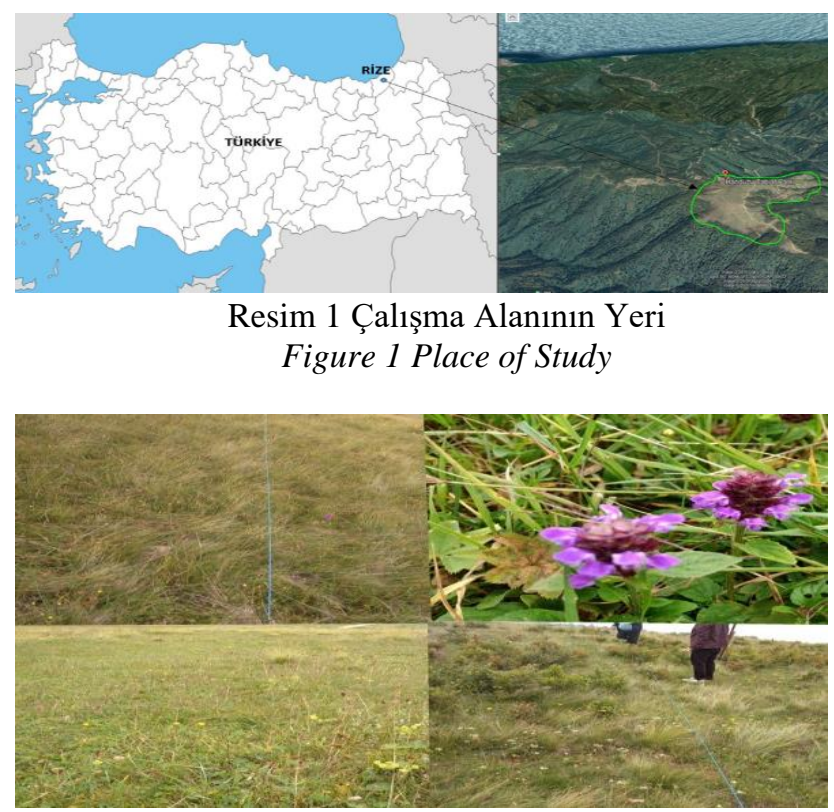

Resim 2 Çalışma Alanından Görüntüler

Figure 2 Images from the Study Area

Metot

Çalışmadan alınan toprak örnekleri Pazar Ziraat ve Doğa Bilimleri Fakültesinde faaliyet gösteren Şemsi Bayraktar Toprak Analiz Laboratuarı'nda analiz edilmiştir. Toprak analizi sonucunda denemenin yürütüldüğü toprakların tuzsuz $(\% 0,078)$, az kireçli $(\% 0,12)$ ve killi özellikte olduğu görülmüştür. Toprağın organik madde miktarı $(\% 1,81)$ ve potasyum içeriği $(4,47 \mathrm{~kg} / \mathrm{da})$ az, fosfor içeriği ise $(2,19 \mathrm{~kg} / \mathrm{da})$ çok az olan deneme toprağ $1,4,66$ olan $\mathrm{pH}$ değeri ile asit reaksiyonu göstermiştir. Uzun yıllar sıcaklık ortalaması $14,3^{\circ} \mathrm{C}$ olurken, çalışma yılında daha yüksek $\left(16,9^{\circ} \mathrm{C}\right)$ olarak tespit edilmiştir. Yağış miktarı $2296 \mathrm{~mm}$ - $1917 \mathrm{~mm}$, nisbi nem \%80-\%81.9 olarak belirlenmiştir (Anonim, 2019). Ölçümler HaziranTemmuz ayında vejetasyonu oluşturan bitkilerin vejetatif gelişimini tamamlayıp, generatif devre içinde bulundukları 
dönemde yani bitkilerin çiçeklenme devresinde yapılmıştır. Türler Türkiye florası yardımı ile teşhis edilerek (Davis, 1965-1985, Davis ve ark., 1988), Türkiye Bitkileri Listesi ve Tubives verilerinden yararlanılarak kontrolleri gerçekleştirilmiştir. Botanik kompozisyonun belirlenmesinde Tosun (1968)'un belirttiği esaslar dikkate alınarak her bir ana hat üzerinde 10 Lup hat olacak şekilde 5 ana hat ölçülmüştür. Lup ölçümlerinde bitkiye rastlanılan Lup alanlarının toplam Lup alanına bölünmesiyle toprağ kaplama alanı belirlenmiştir (Gökkuş ve ark., 1993). Botanik kompozisyonda yer alan bitkilere Gökkuş ve ark. (1993) ve Bakoğlu (1999)'nun belirttikleri esaslar dahilinde -1 ile 10 arasında puanlar verilmiş, daha sonra botanik kompozisyondaki oranları ile çarpılarak tüm türlere ait değerlerin toplanmasıyla mera kalite derecesi ve durum sınıfi bulunmuştur.

\section{Bulgular ve Tartışma}

Çalışmada tespit edilen tür listesi, familyası, toprağ kaplama ve botanik kompozisyon oranı Çİzelge 1'de ve botanik kompozisyonda bulunan türlerin familyalarına göre dağımı Şekil 1'de verilmiştir.

Çizelge 1 Handüzü mera alanı bitki türlerinin familyaları, değer sayıları, toprağı kaplama ve botanik kompozisyon oranlar1, mera dereceleri

Table 1 The families of plant species of Handuzu pasture, number of values, canopy cover and botanical composition rates, pasture degrees

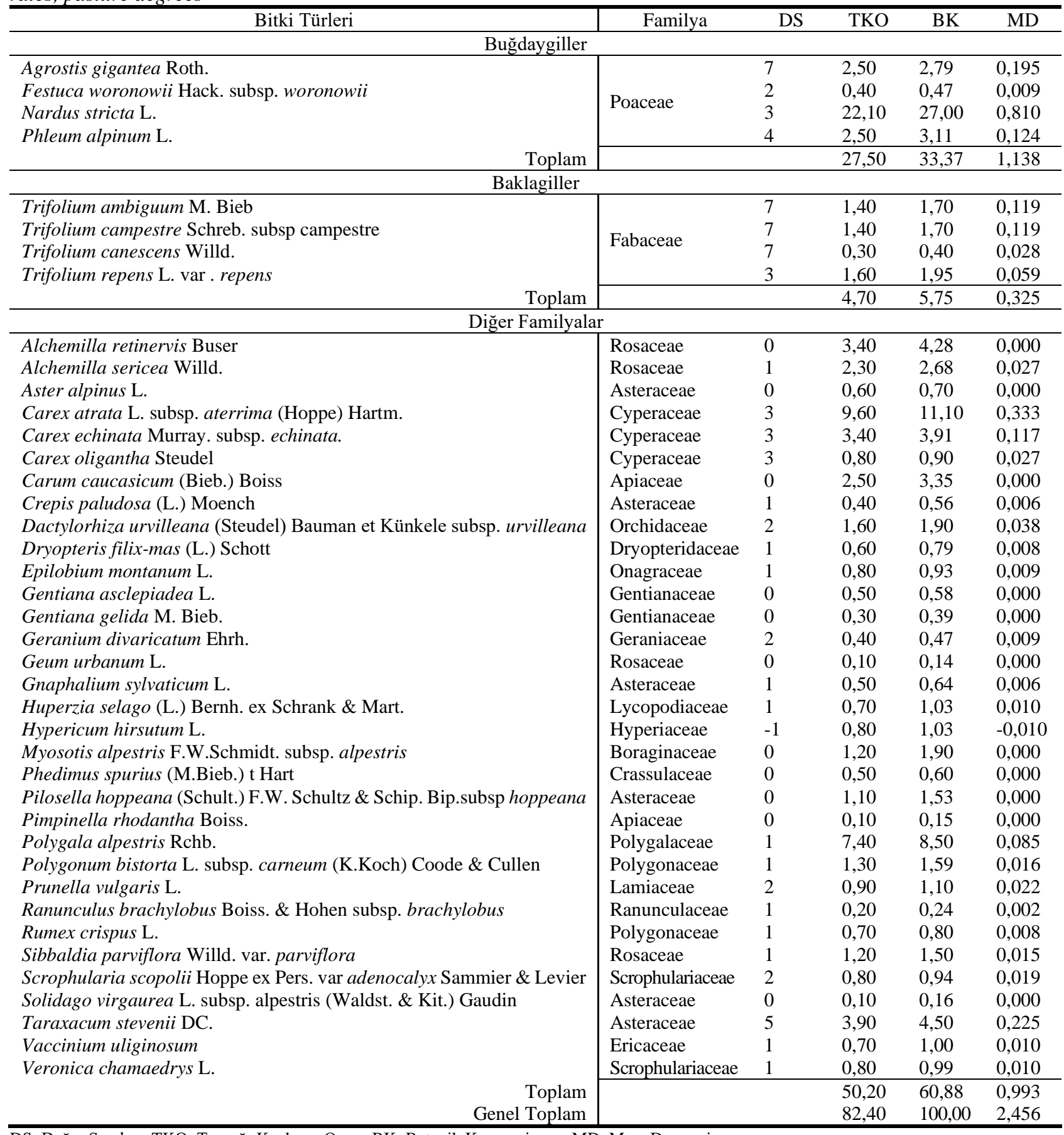

DS: Değer Sayıları, TKO: Toprağı Kaplama Oranı, BK: Botanik Kompozisyon, MD: Mera Derecesi 


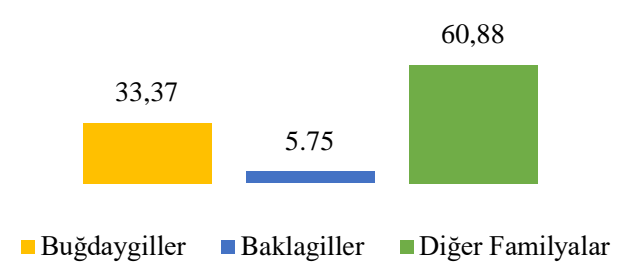

Şekil 1 Botanik kompozisyonda bulunan türlerin familyalarına göre dağılımları (\%).

Figure 1 Distribution of species in botanical composition according to their families (\%)

Çizelge 1'e bakıldığında çalışılan meranın toprağ kaplama oranı \%82,40 olarak bulunmuştur. Vejetasyon etüdünde toplam 41 farklı tür tespit edilmiş ve bunlardan 4 tanesi buğdaygil $(\% 33,37), 4$ tanesi baklagil $(\% 5,75)$ ve 33 tanesi $(\% 60,88)$ diğer familyaya ait bitkilerden oluşmuştur. Mera kalite derecesi 2.456 ile meranın durumunun zayıf olduğu belirlenmiştir. Çalışılan mera vejetasyonu botanik kompozisyonunda bulunan bitkilerden buğdaygillerden k1lotu (Nardus stricta), alp itkuyruğu (Phleum alpinum) ve koca tavusotu (Agrostis gigantea); baklagillerden ak üçgül (Trifolium repens var. repens), pisikkulağı (T. ambiguum) ve üçgül ( $T$. campastre Schreb); diğer familyalardan ise gece saparnası (Carex atrata subsp. aterrima), yayla sütotu (Polygala alpestris) ve gelin göbeği (Taraxacum stevenii DC.) ilk üç sırayı oluşturmaktadır.

Araştırma sonucunda elde edilen bulguların diğer araştırıcılarla (Bakoğlu ve Koç, 2002; Faretörbay, 2007; Bilgin, 2010; Nadir ve ark., 2012; Yavuz ve ark., 2012; Ağın ve Kökten, 2013; Taşdemir, 2015; İspirli ve ark., 2016; Uzun ve ark., 2016; Babalık ve Fakır, 2017; Çınar ve ark., 2019) arasında benzerlik ve farklılıklar bulunmaktadır. Bulgular arasındaki bu farklılıklar; araştırma alanlarının farklı iklim ve toprak özelliklerine sahip olması yanında farklı vejetasyon ölçüm yöntemlerinin kullanılması, araştırmalarda korunan ve otlanan gibi farklı 1slah yöntemlerinin faktör olarak uygulanmasının botanik kompozisyon oranları üzerine etkisinden kaynaklanmaktadır.

\section{Sonuç ve Öneriler}

Bu çalışma yöre meralarında yapılan ilk çalışma olma özelliği göstermesi bakımından büyük önem arz etmektedir. Yapılan çalışma sonucunda bitkilerin toprağ kaplama oranı çok yüksek $(\% 82,40)$, botanik kompozisyonda özellikle baklagil oranının çok düşük $(\% 5,75)$ ve diğer familyadan bitki türlerinin yüksek değerde olduğu $(\% 60,88)$ tespit edilmiştir. Otlanma alanlarında özellikle diğer familyadan türlerin yoğun olarak bulunması mera kalitesinin düşük olduğunun bir göstergesi olarak kabul edilmektedir. Ayrıca çalışılan bölgenin yıllık yağış ortalaması 2296 mm olması, özellikle Nardus sp. ve Carex sp. türlerinin yoğun olmasına etki etmiştir. $\mathrm{Bu}$ türlerin bataklık kenarlarında ve nemli bölgelerde yoğun olarak bulunması ve hayvanlar tarafından otlanmaları tercih edilmediğinden (Gökkuş ve ark., 1995; Anonymous, 2019) bitki botanik kompozisyonunda yüksek oranda olması kaçınılmaz olmuştur. $\mathrm{Bu}$ durum mera durumunun ve sınıfının zayıf olmasına etki etmiştir. Bu durumda meranın iyi forma gelebilmesi için otlatmanın kontrollü yapılması ve üstten tohumlama başta olmak üzere diğer sslah yöntemleri ile kombineli 1slah programı uygulanarak, uygun 1slah yöntemlerinin belirlenmesi ve yeni araştırmaların yapılması gerektiği sonucuna varılmıştır.

\section{References/Kaynaklar}

Ağın Ö, Kökten K. 2013. Bingöl İli Yedisu İlçesi Karapolat Köyü merasının Botanik Kompozisyonunun Belirlenmesi. Tr. Doğa ve Fen Derg., 2 (1): 41-45.

Akdeniz S. 2009. Ayaş-Kazan-Yenikent Arasında Kalan Bölgenin Florası. Yüksek Lisans Tezi, Ankara Üniversitesi Fen Bilimleri Enstitüsü, Ankara.

Anonim. 2016. Türkiye Tarım İstatistikleri Özeti. TÜİK, Ankara. Anonim. 2018. Rize Mera Alan1. (https://rize.tarim.gov.tr /Menu/13/Ekonomi, Erişim tarihi: 24.03.2019)

Anonim. 2019. T.C. Başbakanlık Devlet Meteoroloji İşleri Genel Müdürlüğü, Rize İl Müdürlüğü Kayıtları.

Anonymous. 2019. Matgrass Nardus stricta L. (https://www.invasive.org/browse/subinfo.cfm?sub=6076, Erişim tarihi: 19.03.2019).

Babalık AA, Fakır H. 2017. Korunan ve otlatılan mera alanlarında vejetasyon özelliklerinin karşılaştırılması: Kocapınar Merası örneği. Türkiye Ormancılık Dergisi, 18(3): 207-211.

Bakoğlu A. 1999. Otlatılan ve Korunan İki farklı Mera kesiminin Bazı Toprak ve Bitki Örtüsü Özelliklerinin Karşılaştırılması. Atatürk Üniv. Fen Bil. Ens. Tarla Bit. Anabilim Dalı (Doktora Tezi), Erzurum.

Bakoğlu A, Koç A. 2002. Otlatılan ve Korunan iki Farklı Mera Kesiminin Bazı Toprak ve Bitki Örtüsü Özelliklerinin Karşılaştırılması. I. Bitki Örtüsü Özelliklerinin Karşılaştırılması. Frrat Üniv. Fen ve Müh. Bil. Der., 14 (1), 37-47.

Baykal H, Atamov V. 2016. Floristic Diversity in Başhemşin Valley of Kackar Mountains National Park of Rize, Turkey. Pakistan Journal of Botany, 48 (5): 1871-1876.

Baykal H, Atamov V. 2017. Ethnobotanical Documentation of Plants of Başhemşin Valley, Kaçkar Mountains National Park, Rize, Turkey. Bangladesh Journal of Botany, 46(2): 767-773.

Baykal H, Atamov V. 2018. Isırlık Doğa Parkı ve Çevresinin Floras1. Ot Sistematik Botanik, 25 (2): 151-170.

Baykal H, Atamov V, Yüksek T. 2018. Flora of Tunca Valley Natural Park and environs (Ardeşen-Rize/Turkey). Biological Diversity and Conservation, 11 (2): 9-24.

Bilgin F. 2010. Artvin Ardanuç-Aydın Köyü Yaylası Mera Vejetasyonu ile Bazı Toprak Özelliklerinin Yükseltiye Göre Değişiminin İrdelenmesi. Artvin Çoruh Üniversitesi, Fen Bilimleri Enstitüsü, Yüksek Lisans Tezi, $91 \mathrm{~s}$.

Çınar S, Hatipoğlu R, Avcı M, Yücel C, İnal İ. 2019. Adana İli Tufanbeyli İlçesi Meralarının Vejetasyon Yapısı Üzerine Bir Araştırma. KSÜ Tarım ve Doğa Derg. 22(1):143-152.

Çobanoğlu M. 2012. Güneysu-Çağrankaya nın Flora ve Vejetasyonu (Güneysu-Rize). Yüksek Lisans Tezi, Recep Tayyip Erdoğan Üniversitesi, Fen Bilimleri Enstitüsü, Rize.

Davis PH. 1965-1985. Flora of Turkey and The East Aegean Islands. Vol 1-9, Edinburgh University Press, Edinburgh.

Davis PH, Mill RR, Tan K. 1988. Flora of Turkey and The East Aegean Islands. Vol 10, Edinburgh University Press, Edinburgh.

Faretörbay D. 2007. Palandöken Dağında Farklı Rakıma Sahip Mera Kesimlerinin Bitki Örtülerinin Karşılaştırılması. Atatürk Üniv. Fen Bil. Ens. Tarla Bit. Anabilim Dalı (Yüksek Lisans Tezi), Erzurum.

Gökkuş A, Koç A, Çomaklı B. 1993. "Çayır-Mera Uygulama Kılavuzu”. A.Ü. Ziraat Fakültesi Yayınları No:142, A.Ü. Ziraat Fakültesi Ofset Tesisi, Erzurum. 
Gökkus A, Koç A, Comaklı B. 1995. "Cayır-Mera Uygulama Kılavuzu”, A.Ü. Ziraat Fakültesi Yayınları No:142, A.Ü. Ziraat Fakültesi Ofset Tesisi, Erzurum. (Geliştirilmiş 2. Bask1).

İspirli K, Alay F, Uzun F, Çankaya N. 2016. Doğal Meralardaki Vejetasyon Örtüsü ve Yapısı Üzerine Otlatma ve Topografyanın Etkisi. Türkiye Tarımsal Araştırmalar Dergisi, 3(1), 14-22.

Nadir M, İptaş S, Karadağ Y, Kır H. 2012. Tokat İli Yeşilyurt Köyü Doğal Merasının Botanik Kompozisyon, Kuru Madde Verimi ve Kalitesi. Tarım Bilimleri Araştırma Dergisi 5 (2): 115-117.

Taşdemir V. 2015. Elazığ İli Karakoçan İlçesi Bahçecik Köyü Merasında Verim ve Botanik Kompozisyonunun Saptanması Üzerine Bir Çalışma. Bingöl Üniv. Fen Bil. Ens. Tarla Bit. Anabilim Dalı (Yüksek Lisans Tezi), Bingöl.
Tosun F. 1968. Doğu Anadolu Kıraç Meralarının Islahında Uygulanabilecek Teknik Metodların Tesbiti Üzerine Bir Araştırma. Zirai Araştırma Enstitüsü Araştırma Bülteni No: 29, Ankara.

Türk M, Bayram G, Budaklı E, Çelik N. 2003. Sekonder Mera Vejetasyonunda Farklı Ölçüm Metodlarının Karşılaştırılması ve Mera Durumunun Belirlenmesi. U.Ü. Ziraat Fakültesi Dergisi, Bursa, 17(1): 65-77.

Uzun F, Alay F, İspirli K. 2016. Bartın İli Meralarının Bazı Özellikleri. Türkiye Tarımsal Araştırmalar Dergisi, 3(2), 174 183.

Yavuz T, Sürmen M, Töngel MÖ, Avağ A, Özaydın KA, Yıldız H. 2012. Amasya Mera Vejetasyonlarının Bazı Özellikleri. Tarım Bilimleri Araştırma Dergisi 5 (1): 181-185. 